\title{
Surface Degradation of Ag/W Circuit Breaker Contacts During Standardized UL Testing
}

\author{
Haibo Yu, Yu Sun, M.Tumerkan Kesim, Jason Harmon, Jonathan Potter, S. Pamir Alpay, and Mark Aindow
}

(Submitted June 16, 2015; in revised form July 23, 2015; published online August 6, 2015)

\begin{abstract}
The near-surface microstructure of Ag/W contacts from $120 \mathrm{~V}, 30$ A commercial circuit breakers in the asmanufactured condition and after standardized UL overload/temperature-rise, endurance, and short-circuit testing have been investigated using a combination of $x$-ray diffraction, scanning electron microscopy, energy-dispersive $x$-ray spectroscopy, focused ion beam milling, and transmission electron microscopy. The as-manufactured contacts comprised three constituents: sintered Ag/W composite particles with finegrained Ag and coarse-grained W, coarse-grained pockets of Ag infiltrate, and a nano-crystalline surface $\mathrm{Ag}$ layer. There are also $\mathrm{WO}_{3}$ and $\mathrm{Ag}_{2} \mathrm{O}$ phases at the surface. After $\mathrm{UL}$ overload/temperature-rise testing, there is Ag loss giving a porous W-rich layer at the contact surface. In addition to binary oxides, we observe the formation of $\mathrm{Ag}_{2} \mathrm{WO}_{4}$. After $\mathrm{UL}$ endurance testing, material is swept across the surface by the breaker action giving a $\mathrm{W}$-rich eroded porous surface on one side and a build-up of mixed oxides on the other. After UL short-circuit testing, a $\mathrm{W}$ crust forms due to melting and re-solidification of $\mathrm{W}$ and vaporization of $\mathrm{Ag}$, and mid-plane cracks form due to the severe thermal gradients. There is a strong correlation between the observed microstructural features and the contact resistance measurements obtained from these samples.
\end{abstract}

Keywords circuit breaker contacts, contact resistance, electron microscopy, UL testing

\section{Introduction}

Materials for electrical contacts used in circuit breakers and other electrical switching devices have to meet a stringent set of property requirements including: excellent thermal and electrical conductivity, corrosion resistance, arc erosion resistance, wear resistance, and welding resistance (Ref 1-3). In most cases, no simple metallic alloy can provide the required combination of properties, and metal-matrix composites must be used instead. The metallic matrix phase in such composites is usually a conductive metal (e.g., $\mathrm{Ag}$ or $\mathrm{Cu}$ ) to provide the necessary thermal and electrical properties. The most common reinforcements are refractory materials (e.g., W, WC or Mo) to inhibit contact erosion and tack welding (Ref 4-7). These composites have a variety of applications in electrical switching systems and exhibit different characteristics. Ag/W contacts have excellent arc erosion (Ref 8) and contact wear performance (Ref 9), and they are used where severe arcing is anticipated. The main drawback is the formation of tungsten oxides and/or silver tungstate on the contact surface under repeated switching, which may cause a significant increase of the contact resistance, thereby resulting in contact overheating in service (Ref 10-13). Ag/WC

Haibo Yu, Yu Sun, M. Tumerkan Kesim, S. Pamir Alpay, and Mark Aindow, Department of Materials Science and Engineering, Institute of Materials Science, University of Connecticut, Storrs, CT 06269-3136; Jason Harmon, GE Energy Management - Industrial Solutions, Plainville, CT 06062; and Jonathan Potter, GE Energy Management - Industrial Solutions, Plainville, CT 06062; now at Honeywell Fire Safety, Northford, CT. Contact e-mail: m.aindow@ uconn.edu.

contacts exhibit a higher resistance to contact welding and better arc erosion properties at high currents than $\mathrm{Ag} / \mathrm{W}$ contacts (Ref $10,14,15)$. These $\mathrm{Ag} / \mathrm{WC}$ contacts can be used in similar applications to $\mathrm{Ag} / \mathrm{W}$, however, they are commonly applied in situations where there are severe restrictions on contact heat rise. Ag/Mo contacts have excellent contact resistance stability since the molybdenum oxides that form at the surface are less thermally stable than tungsten oxides and are readily removed by the electrical arc during switching (Ref 16). Contacts based on $\mathrm{Ag} / \mathrm{Mo}$ are mainly applied in device protection switches. Contacts based on $\mathrm{Cu} / \mathrm{W}$ and $\mathrm{Cu} / \mathrm{WC}$ can be used as low-cost alternatives to Ag-based materials in non-oxidizing conditions such as in vacuum-, oil-, or gas-filled devices (Ref 17-19).

Standalone circuit breakers must pass a set of standardized acceptance tests established by Underwriters' Laboratories Inc. (UL), as described in the standard document UL489 (Ref 20). These tests are designed to simulate extreme performance conditions to ensure that the circuit breakers meet certain minimum standards for performance and safety. For breakers that are to be used in residential applications, there are typically three kinds of UL standard tests applied. The first is an overload/ temperature-rise test, in which a current significantly above the rated value $\left(I_{\mathrm{n}}\right)$ is applied for a limited number of on-off operations. The second is an endurance test in which the breaker is switched mechanically for a large number of on-off cycles. The third is a short-circuit test whereby an extremely high current is applied to trip the breaker (Ref 21, 22). While these UL standard tests have been performed routinely on circuit breakers for decades, we are not aware of any detailed studies into the effect of these testing conditions on the microstructures of the contacts. Such studies could provide a valuable insight into the mechanisms of degradation and failure during testing.

In our work, we have been investigating the structure and properties of $\mathrm{Ag} / \mathrm{W}$ contacts of the type used in low-current standalone circuit breakers for domestic applications. The objective of these studies is to develop a basic understanding of the relationships between contact composition, processing, 
and performance in the current generation of $\mathrm{Ag} / \mathrm{W}$ circuit breaker contacts. This will then serve as a reference point for broader research efforts into the development of alternate metallic formulations that might replace the expensive Ag in breakers that operate in air. Here we present a study on the nearsurface microstructures exhibited by commercial $\mathrm{Ag} / \mathrm{W}$ circuit breaker contacts in the as-manufactured condition and after standardized UL testing. These microstructural characteristics have been evaluated using a combination of scanning electron microscopy (SEM), energy-dispersive x-ray spectroscopy (EDXS), focused ion beam (FIB) milling, and transmission electron microscopy (TEM). It is shown that dramatic changes occur in the morphology, structure, and distribution of the phases present at the contact surface, even for contacts from breakers that pass the standard UL tests. The significance of these observations for the properties and performance of the breaker contacts is discussed.

\section{Materials and Experimental Methods}

All of the data reported in this paper were obtained from Ag/ $\mathrm{W}$ contacts of the type used in $120 \mathrm{~V}, 30 \mathrm{~A}$ circuit breakers for residential applications. The contacts were manufactured by Caribe GE (Puerto Rico) using a powder metallurgy approach. Elemental Ag and $\mathrm{W}$ powders were blended together with a small amount $(<1 \%)$ of $\mathrm{Ni}$ as a sintering aid (Ref 6, 23-25), and the blends were pre-processed to produce powders consisting of composite $\mathrm{Ag} / \mathrm{W}$ particles. The composite powder was then compacted into dies and sintered to produce contacts with a diameter of $4.0 \mathrm{~mm}$, a thickness of $1.6 \mathrm{~mm}$, a smooth upper (contact) surface, and a corrugated back surface. Residual porosity in the sintered contacts was eliminated by infiltration with Ag from the back, giving an overall composition for the final contact of $40 \mathrm{Ag}-60 \mathrm{~W}$ (wt.\%). The infiltration process results in a pure Ag layer of up to $150 \mu \mathrm{m}$ in thickness on the back surface; this layer promotes the formation of a strong bond during attachment of the contacts to the Sn-coated $\mathrm{Cu}$ breaker arm by brazing. A description of the brazing process and the braze-joint microstructures that develop has been presented elsewhere (Ref 26).

For this study, $120 \mathrm{~V}, 30$ A circuit breakers in four different conditions were examined: untested breakers and breakers after UL standard overload/temperature-rise, endurance, and shortcircuit testing. Following UL489 (Ref 20), the overload/ temperature-rise tests comprised 50 on-off cycles at $180 \mathrm{~A}$; the endurance tests involved 6000 with load on-off cycles at 30 A followed by 4000 cycles with no current; and the shortcircuit tests consisted of tripping each breaker three times by applying $5000 \mathrm{~A}$ at full voltage. In each case, the breakers undergo calibration checks both before and after the test to determine if the required performance has been achieved.

The breakers were disassembled and the ends were cut off the breaker arms with the $\mathrm{Ag} / \mathrm{W}$ contact attached. While all of the data presented here were obtained from the breaker arms (i.e., the contacts that move during breaker opening or closure), we note that the mating stationary $\mathrm{Ag} / \mathrm{W}$ contacts had the same composition, processing route, and geometry. Moreover, these stationary contacts exhibited similar surface microstructures to the moving contacts both before and after testing. Measurements of contact resistance, $R_{\mathrm{c}}$, were obtained using a singlepoint hemispherical gold probe following the ASTM standard methodology (Ref 27). A Keithley 2400 Source Meter was used as the current source for the measurements (1-100 mA range), while a Keithley 2182A Nanovoltmeter was used to measure the potential difference across the voltage leads. All measurements were obtained under a constant load of $25 \mathrm{~g}$. Three different samples were used, and a total of at least 30 readings of contact resistance were recorded for each test condition. As described in section III below, the contact tips were wiped with ethanol prior to performing the measurements to reduce the effects of surface contamination on the $R_{\mathrm{c}}$ values obtained. It is important to note that $R_{\mathrm{c}}$ is a measure of the surface condition of the individual contacts as a basis for comparison, not the contact resistance measured through the mating breaker contact surfaces as is commonly used in the industry (see, for example, Ref 28).

X-ray diffraction (XRD) was performed on the contact surfaces of selected samples using a Bruker AXS D2 Phaser diffractometer with a $30 \mathrm{kV} \mathrm{Cu} \mathrm{K-} \alpha$ source and a Lynxeye detector. XRD spectra were obtained by scanning over a $2 \theta$ range of $20^{\circ}-60^{\circ}$ at a scan speed of $0.02^{\circ} / \mathrm{s}$ for a total of $2.5 \mathrm{~h}$. The data were analyzed by comparison with standard JCPDS files.

Some of the samples were clamped in a vise-type SEM sample holder for direct examination of the contact surfaces. Others were sectioned by cutting perpendicular to the contact surface through the middle of the contact. These cross sections were mounted in cold-setting epoxy resin loaded with a conductive filler of $\mathrm{Ni}$ powder, ground using successively finer grades of $\mathrm{SiC}$ abrasive papers, and then polished using alumina suspension. Secondary electron (SE) and backscattered electron (BSE) SEM images were obtained from these samples in a JEOL 6335 field emission SEM equipped with an EDAX EDXS system.

Cross-sectional TEM specimens were prepared from the contact surfaces using an FEI Strata 400S dual-beam FIB instrument, which is equipped with a flip-stage and a scanning transmission electron microscopy (STEM) detector for improved final thinning. A 3- $\mu \mathrm{m}$-thick Pt layer was deposited onto the contact surface in situ to protect the surface of the TEM specimen during ion milling. This deposition was performed in two steps: the first $1 \mu \mathrm{m}$ of Pt was deposited using the electron beam to crack the organometallic $\mathrm{Pt}$ precursor, and the remaining $2 \mu \mathrm{m}$ of Pt was deposited using the ion beam. The ion column accelerating voltage used was $30 \mathrm{kV}$ throughout the milling process, but the ion beam currents were reduced iteratively to a value of $9.7 \mathrm{pA}$ during final milling to avoid excessive $\mathrm{Ga}^{+}$implantation and beam damage. The FIB-cut slices were mounted onto Mo Omni grids and attached at two corners to limit mechanical buckling of the samples during final thinning. TEM foils from the contact interiors were prepared by removing the contacts from the breaker arm, grinding to a thickness of $\approx 100 \mu \mathrm{m}$, punching a 3-mm-diameter disk, and then twin-jet electrolytic polishing to perforation in a Struers TenuPol-5 electro-polishing apparatus. The electro-polishing was performed using an electrolyte of $9 \%$ distilled water, $73 \%$ ethanol, $10 \%$ butoxyethanol, and $8 \%$ perchloric acid (by volume) at $-15{ }^{\circ} \mathrm{C}$ and $10 \mathrm{~V}$. The electropolished specimens were then $\mathrm{Ar}^{+}$ion milled to remove the topographic effects arising from preferential dissolution of the $\mathrm{Ag}$ during electro-polishing. The ion milling was performed at an accelerating voltage of $3 \mathrm{kV}$ with liquid nitrogen cooling in the cold stage of a Gatan model 600 Duo-mill; cooling of the sample during milling was necessary to minimize the formation 
of secondary defects in the soft Ag phase. The FIB-cut cross sections and the TEM foils were examined in an FEI Tecnai T12 TEM and in a JEOL JEM-2010 FasTEM operating at accelerating voltages of 120 and $200 \mathrm{kV}$, respectively; both of these instruments are equipped with EDAX ultra-thin window EDXS systems.

\section{Results}

Examples of the samples cut from the breaker arms in untested breakers and in breakers that had undergone UL overload/temperature-rise, endurance, and short-circuit tests are shown in Fig. 1. For the sample from the untested breaker (Fig. 1a), both the circular contact and the breaker arm exhibit a characteristic silver-gray metallic sheen as one might expect for an $\mathrm{Ag} / \mathrm{W}$ cermet and an $\mathrm{Sn}$-coated $\mathrm{Cu}$ strap, respectively. We note, however, that there was some minor discoloration particularly in the center of the contact surface. Much more extensive discoloration of the metal was noted for the samples from the tested breakers (Fig. 1b-d). This was accompanied by the formation of a sooty deposit, particularly in the case of the samples from the breakers that had been subjected to endurance and short-circuit tests. In preliminary experiments, the deposited material caused complications with both the measurement of contact resistance and the evaluation of surface microstructure. As such, all samples were rinsed in, or swabbed gently with, ethanol to remove any loose surface material before performing contact resistance measurements or microstructural characterization. We note that this procedure is unlikely to have a significant effect on the properties or structures of the contacts since the mating contacts meet with a mechanical swiping motion during breaker closure (Ref 29-32).

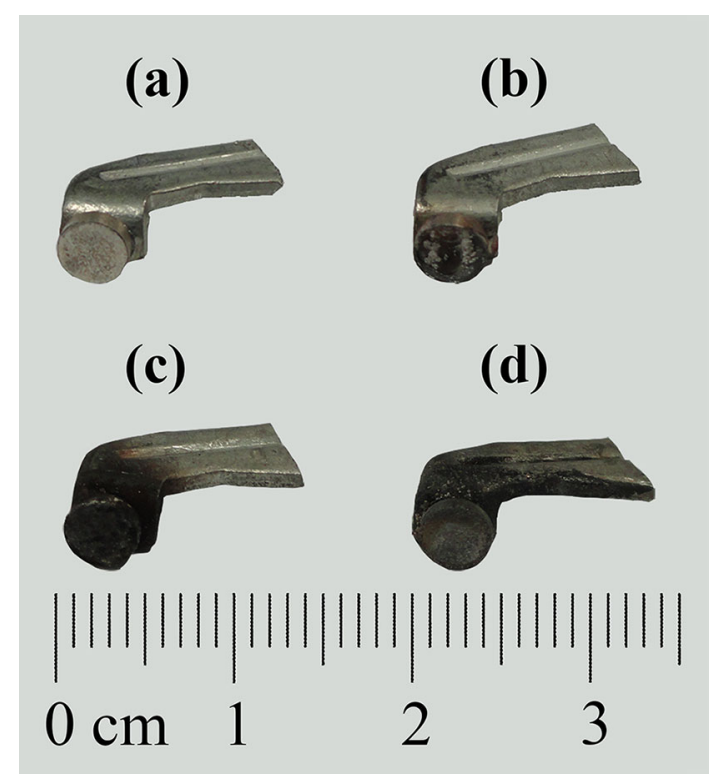

Fig. 1 Examples of samples cut from the circuit breaker arms with the circular $\mathrm{Ag} / \mathrm{W}$ contact tips attached: (a) untested breaker; (b) after overload/temperature-rise testing; (c) after endurance testing; (d) after short-circuit testing

\subsection{Contact Resistance}

The contact resistance data obtained from the rinsed and wiped contacts are summarized in Table 1 . The $\mathrm{Ag} / \mathrm{W}$ contacts from the untested circuit breakers exhibit consistently low contact resistances with a mean of $R_{\mathrm{c}}=1.68 \mathrm{~m} \Omega$ and a standard deviation of $0.30 \mathrm{~m} \Omega$. All of the contacts from the UL-tested breakers exhibited higher contact resistance values, with the most pronounced differences being for those from endurance and short-circuit tested breakers. The mean value of $R_{\mathrm{c}}$ for contacts from the overload/temperature-rise tested breakers $(3.02 \mathrm{~m} \Omega)$ is about twice that for the untested breakers, while the values for contacts from endurance and short-circuit tested breakers are approximately three and four orders of magnitude higher, respectively (2.13 and $12.88 \Omega$, respectively). The standard deviations reveal that while the $R_{\mathrm{c}}$ values for contacts from overload/temperature-rise tested breakers are very consistent, there is much greater variability in the values obtained for contacts from endurance and shortcircuit tested breakers. We note that this variability in $R_{\mathrm{c}}$ was also observed from location to location on each contact surface, rather than being just sample-to-sample variation. The microstructural origins of this variability are considered in sections 3.4 and 3.5 below.

\subsection{Phase Identification by XRD}

The crystalline phases present at the contact surfaces were identified using XRD data obtained in Bragg-Bretano geometry from the circular contact surfaces of the $\mathrm{Ag} / \mathrm{W}$ contact tips. Representative examples of the XRD data obtained from untested breaker contacts and from contacts in overload/ temperature-rise, endurance, and short-circuit tested breakers are shown in Fig. 2. The data from the untested breaker tips (Fig. 2a) exhibit four strong peaks in the $2 \theta$ range of $20^{\circ}-60^{\circ}$. The peaks at $38.21^{\circ}$ and $44.40^{\circ}$ correspond to those expected for the $\{111\}$ and $\{200\}$ planes, respectively, in face-centered cubic (FCC) Ag with a lattice parameter of $a_{0}=0.4086 \mathrm{~nm}$. Similarly, those at $40.35^{\circ}$ and $58.34^{\circ}$ correspond to the $\{110\}$ and $\{200\}$ peaks, respectively, for body-centered cubic (BCC) $\mathrm{W}$ with $a_{0}=0.3165 \mathrm{~nm}$. These four peaks are also present in the data from the overload/temperature-rise and endurancetested contacts (e.g., Fig. 2c and e), although in both cases the W peaks are more intense than the Ag peaks, whereas in the data from the untested breaker contacts the converse is true. This suggests that there may be some Ag loss or re-distribution during testing, and indeed in the XRD data from the shortcircuit tested contacts only the two $\mathrm{W}$ peaks are present, as shown in Fig. 2(g).

When the data are plotted on an enlarged vertical scale weak peaks from minority phases are observed. The data from the untested breaker contacts (Fig. 2b) contain additional peaks corresponding to the equilibrium triclinic polymorph of $\mathrm{WO}_{3}$ $\left(a_{0}=0.7309 \mathrm{~nm}, \quad b_{0}=0.7522 \mathrm{~nm}, \quad c_{0}=0.7678 \mathrm{~nm}, \quad \alpha=\right.$ $\left.88.81^{\circ}, \beta=90.92^{\circ}, \gamma=90.93^{\circ}, \mathrm{P} \overline{1}\right)(\operatorname{Ref} 33)$. There is also a single peak at the position expected for $\{0002\}$ in the layered hexagonal modification of the $\mathrm{Ag}_{2} \mathrm{O}$ structure first reported by Kabalkina et al. (Ref 34) $\left(a_{0}=0.3072 \mathrm{~nm}, c_{0}=0.4941 \mathrm{~nm}\right.$, $\left.\gamma=120^{\circ}, \mathrm{P} \overline{\mathrm{m}} \mathrm{m}\right)$ and a single peak at $52.27^{\circ}$ corresponding to $\{200\}$ for FCC Ni $\left(a_{0}=0.3524 \mathrm{~nm}\right)$. These peaks were also present in the data from the overload/temperature-rise tested contacts (Fig. 2d), but there are additional weak peaks corresponding to the orthorhombic $\mathrm{Ag}_{2} \mathrm{WO}_{4}$ phase $\left(a_{0}=\right.$ 
Table 1 Contact resistance values measured for $\mathrm{Ag} / \mathrm{W}$ contacts from untested breakers and from breakers after standard UL overload/temperature-rise, endurance, and short-circuit tests

\begin{tabular}{lrrr}
\hline & Mean $\boldsymbol{R}_{\mathbf{c}}, \mathbf{m} \boldsymbol{\Omega}$ & Standard deviation, $\mathbf{m} \boldsymbol{\Omega}$ & Number of measurements \\
\hline Untested & 1.68 & 0.30 & 33 \\
Overload/temperature-rise & 3.02 & 0.94 & 36 \\
Endurance & 2130.76 & 1730.61 & 38 \\
Short-circuit & $12,880.01$ & $38,439.06$ & 32 \\
\hline
\end{tabular}

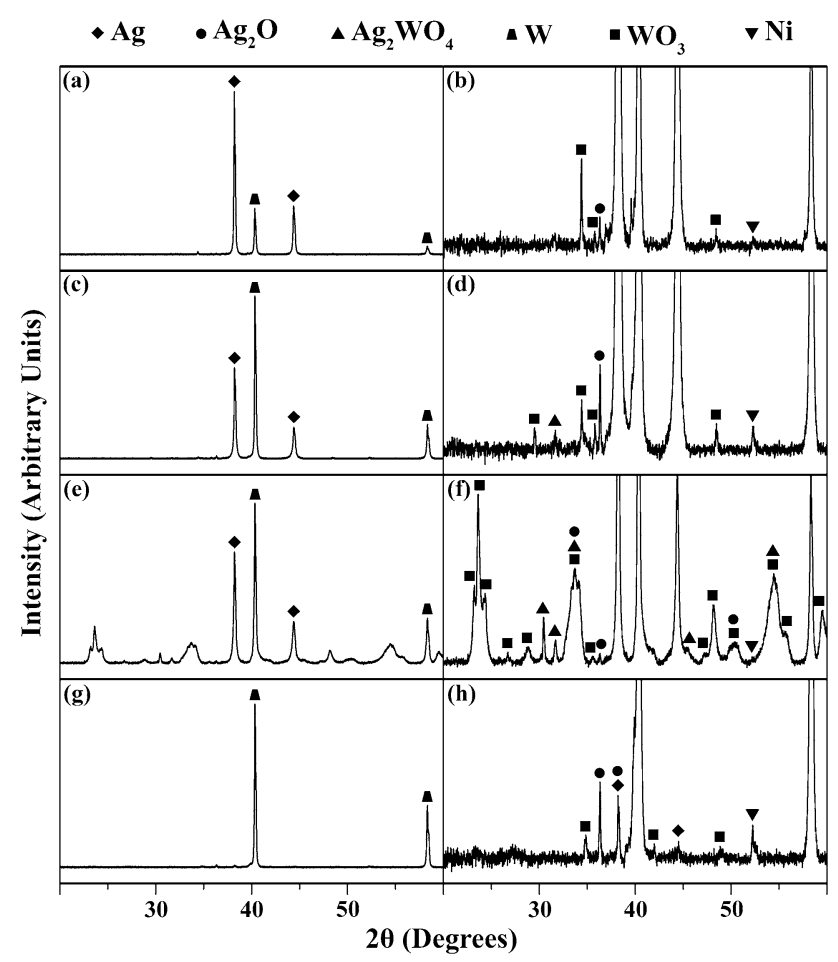

Fig. 2 XRD data obtained from contact tips in breakers: $(a, b)$ untested; (c, d) after overload/temperature-rise testing; (e, f) after endurance testing; and $(\mathrm{g}, \mathrm{h})$ after short-circuit testing. In each case, the figure on the left $(\mathrm{a}, \mathrm{c}, \mathrm{e}, \mathrm{g})$ is at full scale showing the main peaks, whereas the figure on the right $(b, d, f, h)$ is the same dataset on an expanded vertical scale to reveal the weak peaks from minority phases

$\left.1.0890 \mathrm{~nm}, b_{0}=1.2030 \mathrm{~nm}, c_{0}=0.5920 \mathrm{~nm}, \operatorname{Pn} 2 \mathrm{n}\right)($ Ref 2, $35,36)$ in these data. The minority phase peaks were much more intense in the XRD data from the endurance-tested contacts (Fig. 2f), and indeed several of these peaks are clearly present even in the full-scale plot (Fig. 2e). Here again, all of these peaks could be indexed to one or more of triclinic $\mathrm{WO}_{3}$, orthorhombic $\mathrm{Ag}_{2} \mathrm{WO}_{4}$, hexagonal $\mathrm{Ag}_{2} \mathrm{O}$, and FCC Ni. The minority phase peaks in the data from the short-circuit tested contacts (Fig. 2h) were much weaker and corresponded to the $\mathrm{Ag}, \mathrm{WO}_{3}, \mathrm{Ag}_{2} \mathrm{O}$, and $\mathrm{Ni}$ phases, with no evidence for the presence of $\mathrm{Ag}_{2} \mathrm{WO}_{4}$.

\subsection{Microstructure of Contacts from Untested Breakers}

Firstly, the surface structure of the Ag/W contacts from the untested breakers was investigated using SE imaging, BSE imaging, and EDXS analysis in the SEM. A selection of typical images is shown in Fig. 3. The overall morphology of the contact surface was revealed in low-magnification SE images such as Fig. 3(a). While the surface is in general flat and smooth, there are some minor variations in topography and in surface contrast, which may relate to the discoloration observed optically in Fig. 1(a). The topographical detail was revealed in higher-magnification SE images such as Fig. 3(b). There is fine-scale (sub- $\mu \mathrm{m})$ surface roughness evident in such images together with occasional dark features that resemble residual pores from the powder metallurgy processing of these materials. The character of the surface features is revealed more clearly in BSE images such as Fig. 3(c), which was obtained from the same area as Fig. 3(b). There are three distinct levels of contrast in such images: black features that correspond to pores or cracks, with dark and light gray regions corresponding to the majority of the metal surface. Since the contact comprised Ag and $\mathrm{W}$, which are essentially immiscible and have rather different atomic numbers $(Z=47$ and 74 for $\mathrm{Ag}$ and $\mathrm{W}$, respectively), the different levels of gray are presumably compositional contrast with the light gray being the high- $Z$ $\mathrm{W}$ and the dark gray being the lower-Z Ag. This is consistent with the average surface composition of $89.4 \% \mathrm{Ag}, 7.7 \% \mathrm{~W}$, and $2.9 \% \mathrm{O}$ (wt. \%) measured from this region by acquiring EDXS data while scanning the beam repeatedly over the field of view. Both the area fraction of the bright contrast in Fig. 3(c) and the $\mathrm{W}$ content measured by EDXS are far lower than those anticipated for $\mathrm{W}$ on the basis of the overall contact composition $(40 \% \mathrm{Ag}, 60 \% \mathrm{~W})$, and the reasons for this are revealed in BSE SEM images obtained from cross-sectional samples such as those shown in Fig. 4.

Figure 4(a) is an overall low-magnification view showing the smooth upper contact surface, the corrugated lower surface, the excess Ag layer, the braze joint, and the Sn-coated $\mathrm{Cu}$ breaker arm; each of these regions exhibits a different contrast in the BSE image due to differences in overall composition and hence in backscattering coefficient. There is some residual porosity present both within the $\mathrm{Ag} / \mathrm{W}$ contact and at the contact surface, which is consistent with the results from surface imaging such as the examples shown in Fig. 3. A higher-magnification BSE image is shown in Fig. 4(b). Here again, the light gray regions are $\mathrm{W}$, the darker gray regions are $\mathrm{Ag}$, and the black features are residual porosity. The mounting media also appear very dark because it comprised a mixture of Ni powder $(Z=28)$ and polymer, so we would expect a much lower backscattered yield from the mount than from Ag or W. Images such as these reveal that there is a Ag-rich surface layer of up to $7 \mu \mathrm{m}$ in thickness, which would help to explain the apparent discrepancy between the overall contact composition, the measured surface composition, and the amount of exposed $\mathrm{W}$ revealed in BSE images such as Fig. 3(c).

A more detailed investigation into the microstructure of these contacts was performed using TEM, and a summary of 

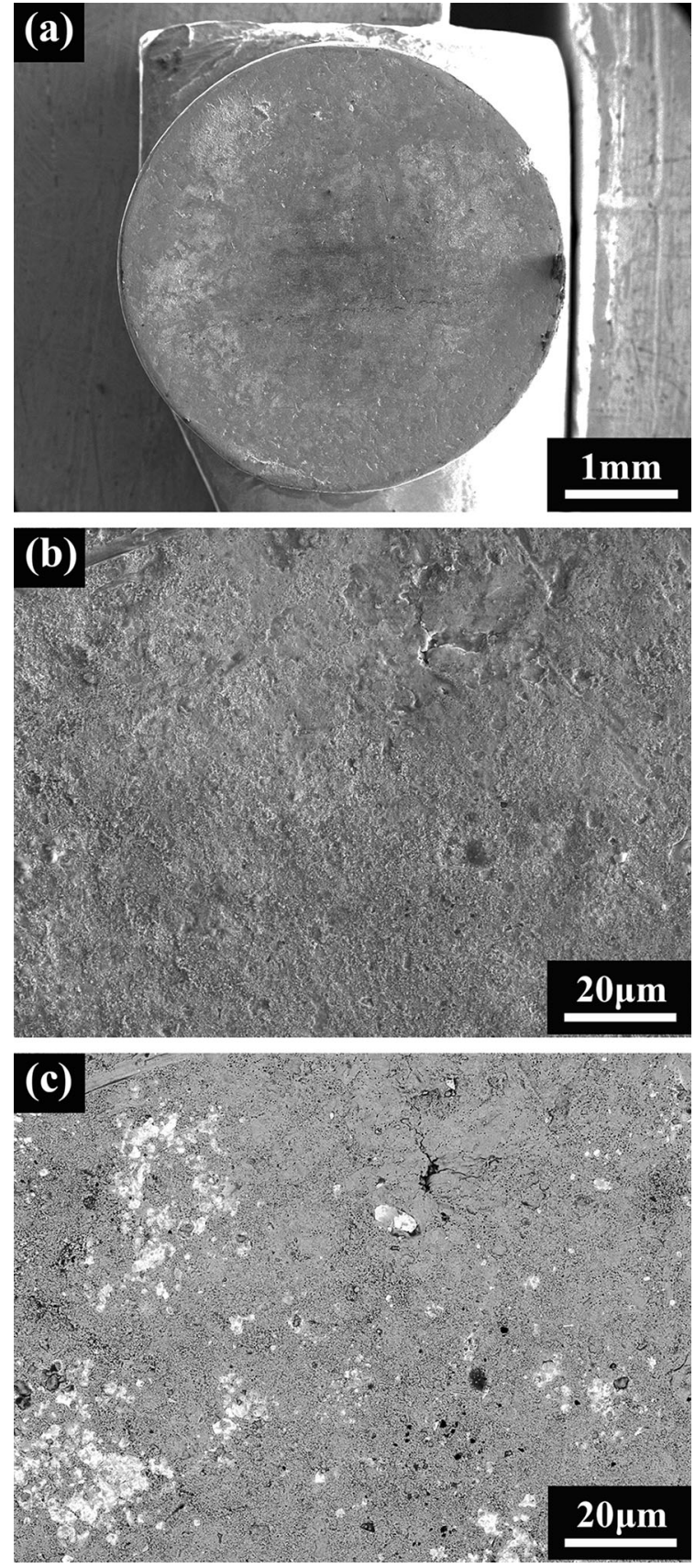

Fig. 3 Examples of SEM data obtained from the contact surface of the $\mathrm{Ag} / \mathrm{W}$ contacts from untested breakers: (a) overall SE image; (b) higher-magnification SE image; (c) BSE image obtained from the region shown in (b)

these observations is presented in Fig. 5. Images obtained from FIB-cut cross sections through the contact surface revealed that the Ag-rich surface layer comprised nano-crystalline Ag. This layer extends across the whole surface with a few nm of nanocrystalline Ag even on the regions with "exposed" W. A BF image showing an example of such a region is shown in Fig. 5(a). Images of the interior of the contact obtained from electro-polished and ion-milled foils show that there are two distinct types of microstructure: fine-grained (100-500 nm) Ag mixed with coarse-grained $(\gg 1 \mu \mathrm{m}) \mathrm{W}$ as shown in Fig. 5(b), and coarse-grained $(\gg 1 \mu \mathrm{m})$ pockets of pure Ag as shown in
Fig. 5(c). These regions presumably correspond to the composite powder particles and the infiltrated Ag used to fill the residual porosity, respectively. The overall microstructure is summarized schematically in Fig. 5(d): the bulk of the interior comprised sintered composite $\mathrm{Ag} / \mathrm{W}$ particles with coarsegrained $\mathrm{W}$ and fine-grained $\mathrm{Ag}$; the residual porosity from the sintering process is filled with a coarse-grained $\mathrm{Ag}$; the surface is covered by a thin layer of nano-crystalline $\mathrm{Ag}$.

\subsection{Microstructure of Contacts from Overload/Temperature- Rise Tested Breakers}

SEM was used to observe the surface morphology and nearsurface microstructure in the $\mathrm{Ag} / \mathrm{W}$ contacts from overload/ temperature-rise tested breakers, and a selection of typical images is presented in Fig. 6. The overall contact surface morphology was revealed in low-magnification SE images such as Fig. 6(a); the surface is rougher and more uneven than that for the untested breakers (Fig. 3a), and there are more obvious variations in surface contrast, which may be related to the extensive discoloration revealed in Fig. 1(b). Higher-magnification SE images, such as Fig. 6(b), show that the contact surface is porous with protruding particulate features. The average surface composition measured from this region is $45.6 \% \mathrm{Ag}, 49.4 \% \mathrm{~W}$, and $5.0 \% \mathrm{O}$ (wt. \%); this is lower in $\mathrm{Ag}$ and higher in $\mathrm{W}$ and $\mathrm{O}$ than the surface composition of the contacts from untested breakers, but is still W-lean when compared with the overall composition of the contact.

The phase distribution was revealed in BSE images obtained from metallographic cross sections through the contacts. Figure 6(c) is a low-magnification BSE image of the overall metallographic cross section, showing that the pore density at the contact surface is significantly higher than for the untested contacts. Higher-magnification BSE images such as Fig. 6(d) revealed that the Ag-rich surface layer observed on untested contacts is no longer present, and there is instead a highly porous surface layer of up to $30 \mu \mathrm{m}$ in thickness. Point EDXS analyses on the metallographic cross sections indicate that the layer comprised a mixture of $\mathrm{Ag}, \mathrm{W}$, and oxide phases. However, due to the porosity and topography of this layer, it was not possible to produce TEM samples from the surface to investigate the distribution of these phases further.

\subsection{Microstructure of Contacts from Endurance-Tested Breakers}

Examples of the SEM data obtained from contacts in breakers subjected to endurance tests are presented in Fig. 7: SE images from the contact surface are shown in Fig. 7(a-c), and BSE images from metallographic cross sections are shown in Fig. 7(d-f). Low-magnification images (e.g., Figure 7a \& d) show that the surface is very rough and uneven with very large variations in contrast from location to location. The crosssectional images (Fig. 7d) also reveal that there is a variation across the surface with more significant loss of materials from the surface on the right-hand side than the left. We note that the plane of the cross section contains the swiping direction of the breaker closure, and that the contact tip on the breaker arm swipes across the fixed contact from right to left in this image. Thus, the region in which the surface erosion is more pronounced is the point at which the breaker arm contact first meets the fixed contact.

Higher-magnification SE images revealed that there were two types of topographic detail on the surface. The first type 

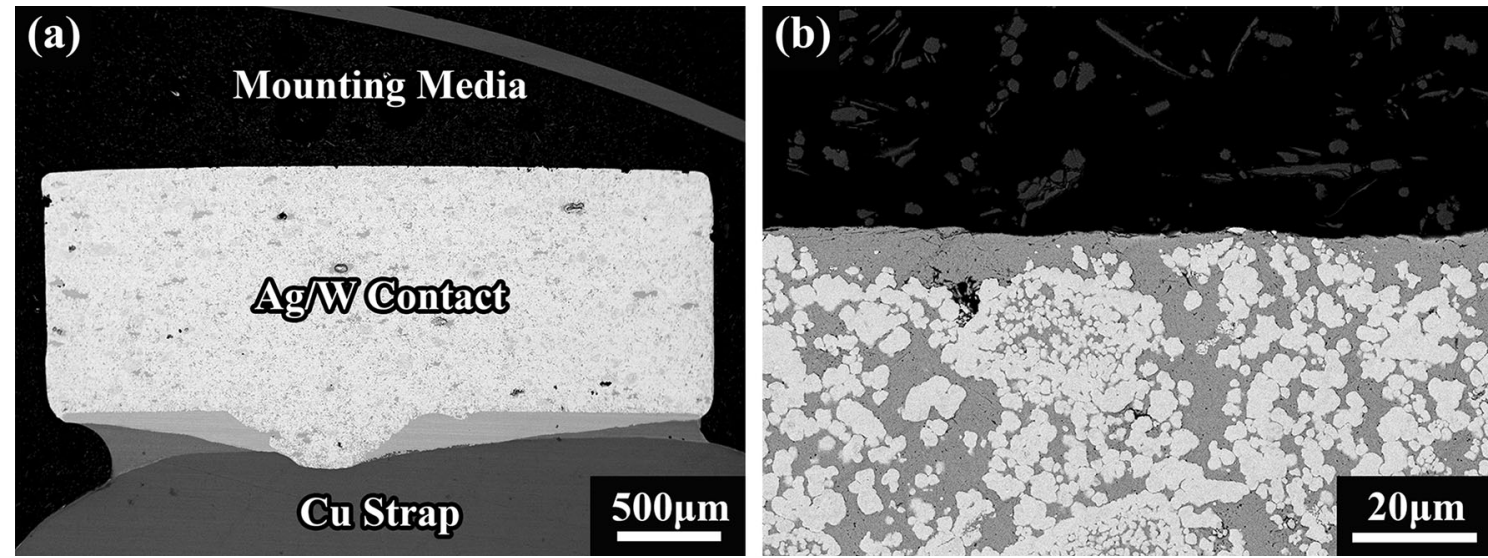

Fig. 4 Examples of BSE SEM images obtained from metallographic cross sections through the Ag/W contacts on Cu breaker arms from untested breakers: (a) overall cross-sectional view through the contact; (b) higher-magnification image of the region near the contact surface
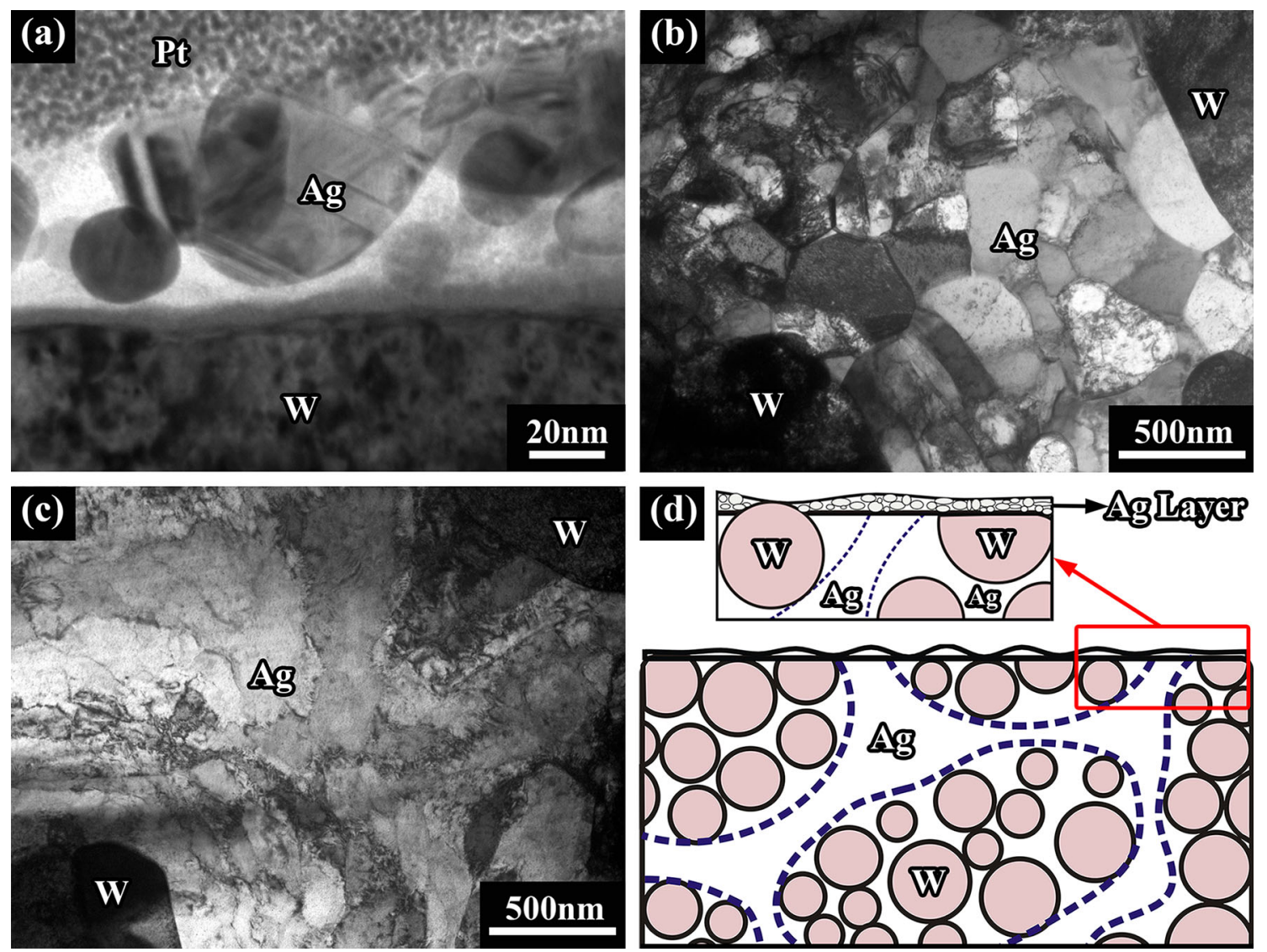

Fig. 5 Examples of TEM data obtained from the Ag/W contacts from untested breakers: (a) high-magnification BF image of a FIB-cut cross section through the contact surface; (b-c) lower-magnification BF images of the contact interior revealing the presence of two forms of Ag with different microstructures. (d) Schematic diagram of the phase distribution for Ag and W; the inset shows the near-surface microstructure in more detail

(Fig. 7b) consists of relatively smooth flat "plateau" regions, separated by rough depressions with undulations on the scale of microns. These regions are more prevalent on the side of the contact that exhibited less obvious erosion. Such areas are decorated by a large number of particulate features up to $1 \mu \mathrm{m}$ across. In cross-sectional BSE images (Fig. 7e), such regions exhibit a fairly dense surface layer, up to $30 \mu \mathrm{m}$ in thickness.
This layer contained through-thickness cracks and large pores were present between the layer and the $\mathrm{Ag} / \mathrm{W}$ mixture below. The compositions measured from such areas by EDXS lay in the range $18-22 \% \mathrm{Ag}, 63-64 \% \mathrm{~W}$, and $14-18 \% \mathrm{O}$ (wt. \%). Thus, there is far less Ag but more $\mathrm{W}$ and $\mathrm{O}$ at the contact surface in such regions than for contacts from untested or overload/temperature-rise tested breakers. 

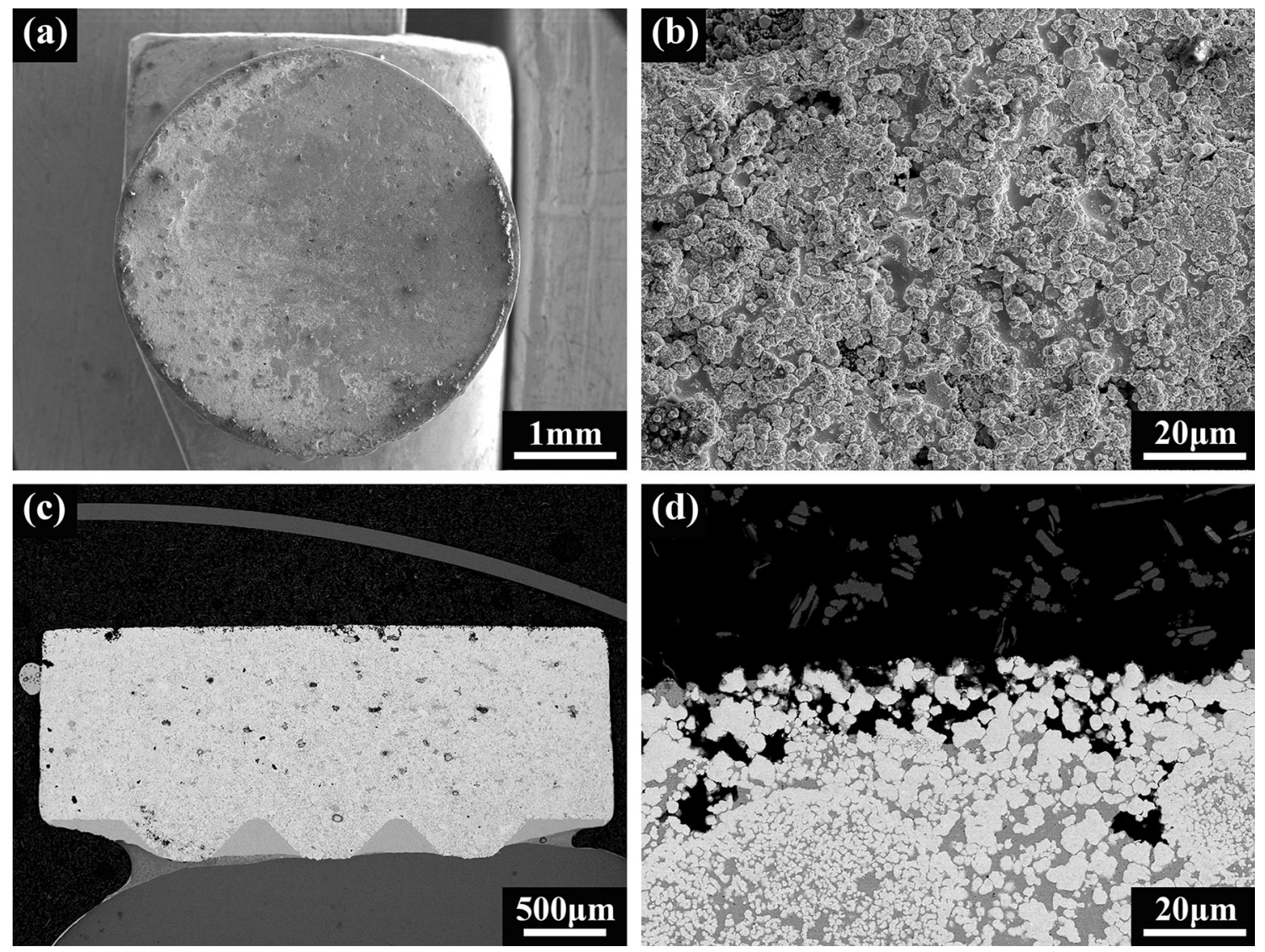

Fig. 6 Examples of SEM data obtained from the Ag/W contacts from breakers subjected to overload/temperature-rise tests: (a) and (b) SE images of the contact surface; (c) and (d) BSE images obtained from a metallographic cross section through the contact
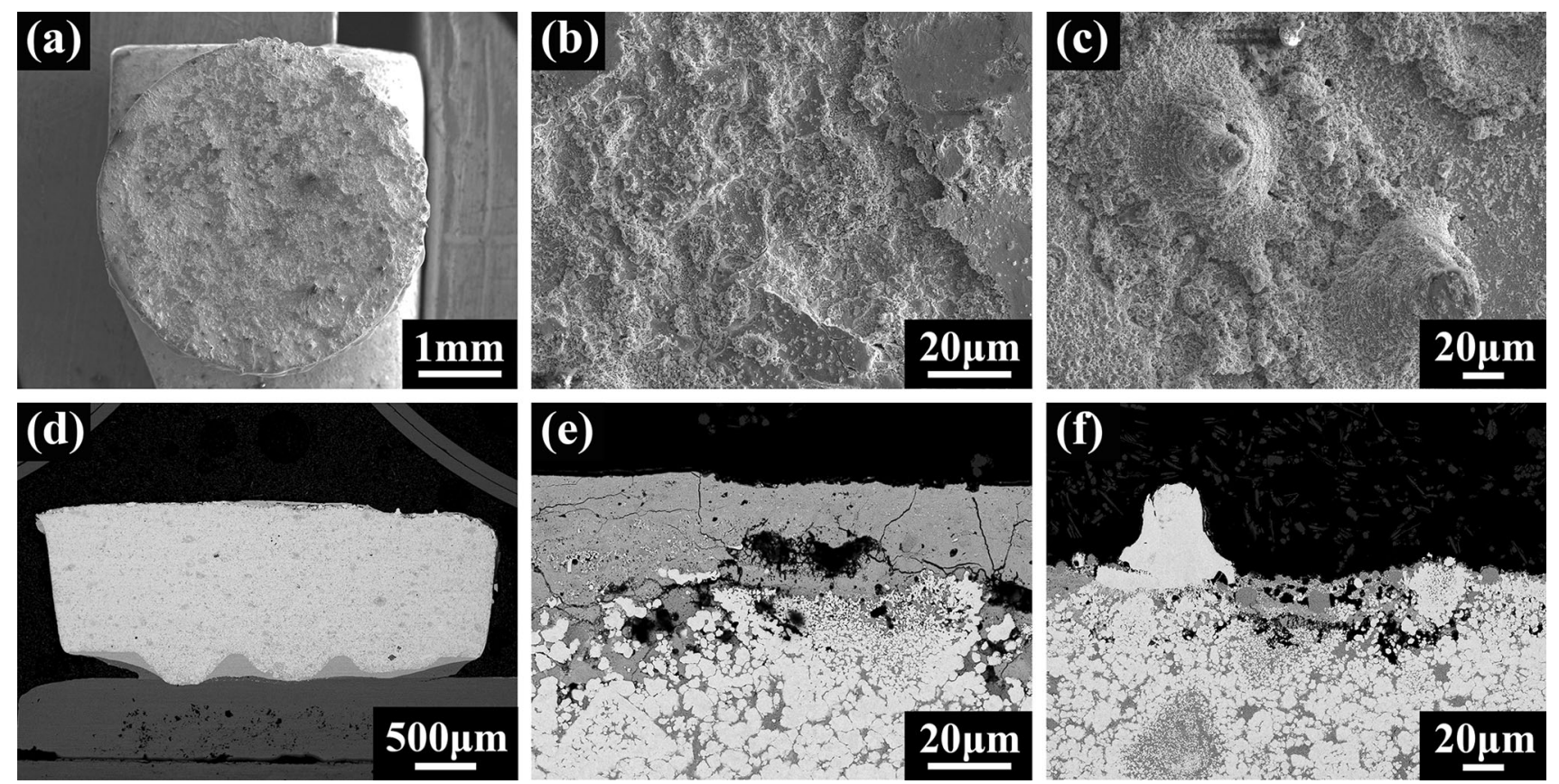

Fig. 7 Examples of SEM data obtained from the Ag/W contacts from breakers subjected to endurance tests: (a-c) SE images of the contact surface; (d-f) BSE images obtained from a metallographic cross section through the contact 

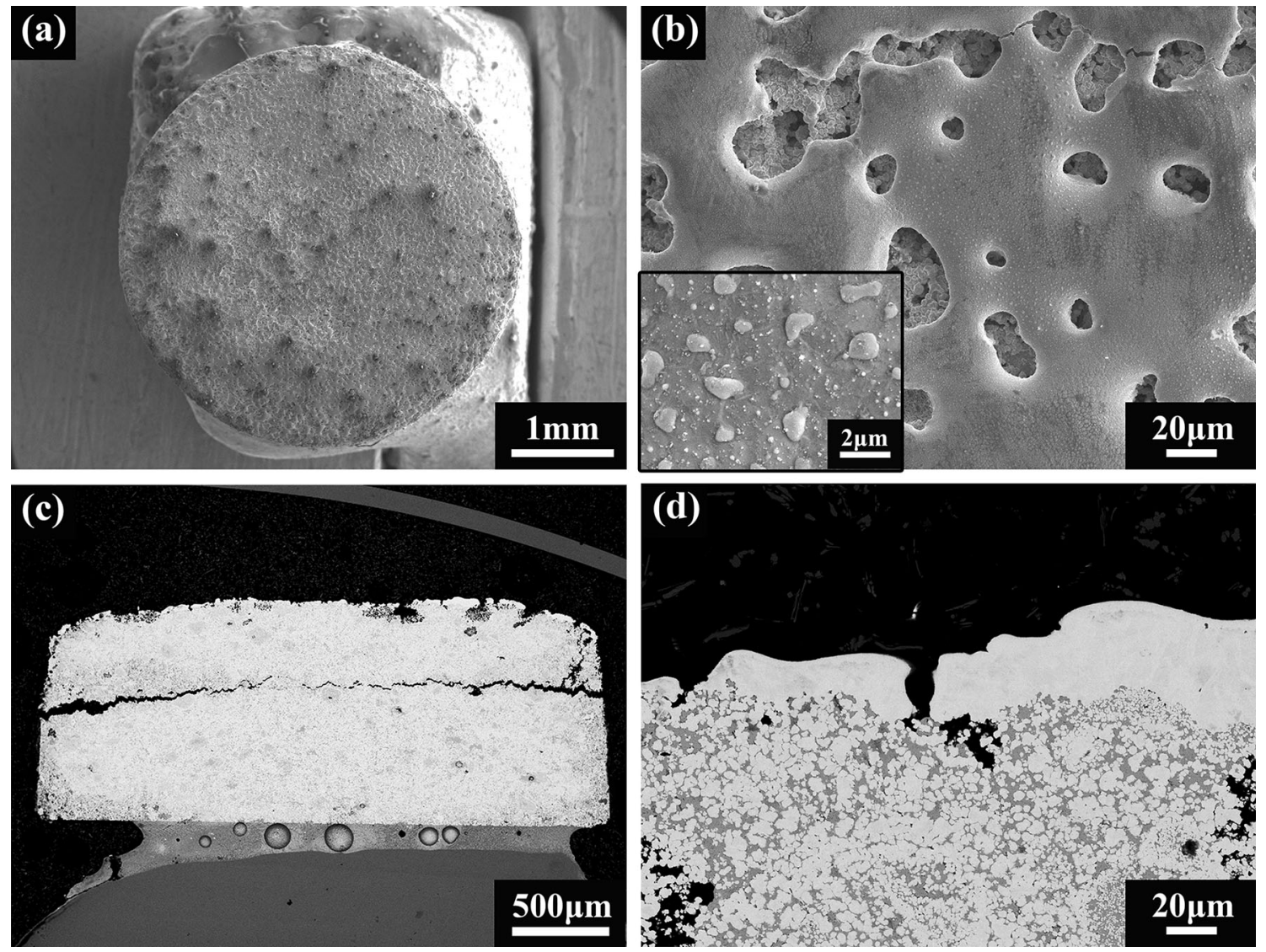

Fig. 8 Examples of SEM data obtained from the $\mathrm{Ag} / \mathrm{W}$ contacts from breakers subjected to short-circuit tests: (a) and (b) SE images of the contact surface; (c) and (d) BSE images obtained from a metallographic cross section through the contact

The second type of region (Fig. 7c) was more representative of the heavily eroded side of the contact. Such regions exhibit nodular protrusions tens of microns in height distributed across smoother undulating regions of the surface, and here again the surface is decorated heavily with particles. The EDXS measurements from such areas reveal that they are enriched in $\mathrm{W}$ as compared to the first type of region, with overall compositions of $12-15 \% \mathrm{Ag}, 70-80 \% \mathrm{~W}$, and $6-15 \% \mathrm{O}$. Higher-magnification BSE images such as Fig. 7(f) show that the nodules exhibit uniform bright contrast, and point EDXS analyses indicate that these nodules comprised pure $\mathrm{W}$. The areas surrounding the nodules are highly porous and exhibit mixtures of bright and dark contrast consistent with this being a mixture of $\mathrm{Ag}, \mathrm{W}$, and oxide phases.

Here again, the complexity of the microstructure, together with the porosity and topography of the surface, precluded the use of TEM to investigate the distribution of these phases further.

\subsection{Microstructure of Contacts from Short-Circuit Tested Breakers}

The SEM data obtained from contacts in breakers that had been subjected to short-circuit tests revealed a very different surface topography and phase distribution; examples of these data are presented in Fig. 8. The low-magnification SE images (Fig. 8a) reveal a rather rough overall topography with occasional nodular features similar to those seen on the eroded contact surfaces for the endurance-tested breakers. However, in higher-magnification SE images, such as Fig. 8(b), most of the surface appears much smoother consisting of a continuous layer with large pores up to $50 \mu \mathrm{m}$ in diameter. It is the distribution of these pores that gives the overall rough appearance at lower magnifications. EDXS data obtained from such regions gave an average surface composition of $5.0 \% \mathrm{Ag}, 91.5 \% \mathrm{~W}$, and $3.5 \%$ $\mathrm{O}$ (wt. \%); thus, the layer is highly enriched in $\mathrm{W}$ and the surface $\mathrm{O}$ content is similar to that for the contacts from the untested breakers. We note that images obtained at yet higher magnifications, such as the inset to Fig. 8(b), reveal a distribution of fine sub-micron particles distributed across the surface of the W-rich layer. These particles are too small to obtain EDXS measurements of composition in the SEM without interference from the underlying layer, but by comparing point analyses obtained with the beam on and off these particles it is clear that they are highly enriched in Ag.

Low-magnification BSE images such as Fig. 8(c) obtained from metallographic cross sections through the contacts reveal profound changes in the contact geometry and integrity. Most of the contacts from short-circuit tested breakers contained cracks through the mid-plane of the contact parallel to the contact surface, similar to those reported previously by Wingert [37]. There was also much more extensive material loss at the contact edges than in any of the other types of contact leading to a more rounded or dome-like morphology. The contact surfaces exhibited a bright crust with large pores, and highermagnification images such as Fig. 8(d) show that this surface layer is up to $50 \mu \mathrm{m}$ in thickness. The EDXS data obtained from this layer indicate that the crust is essentially pure 

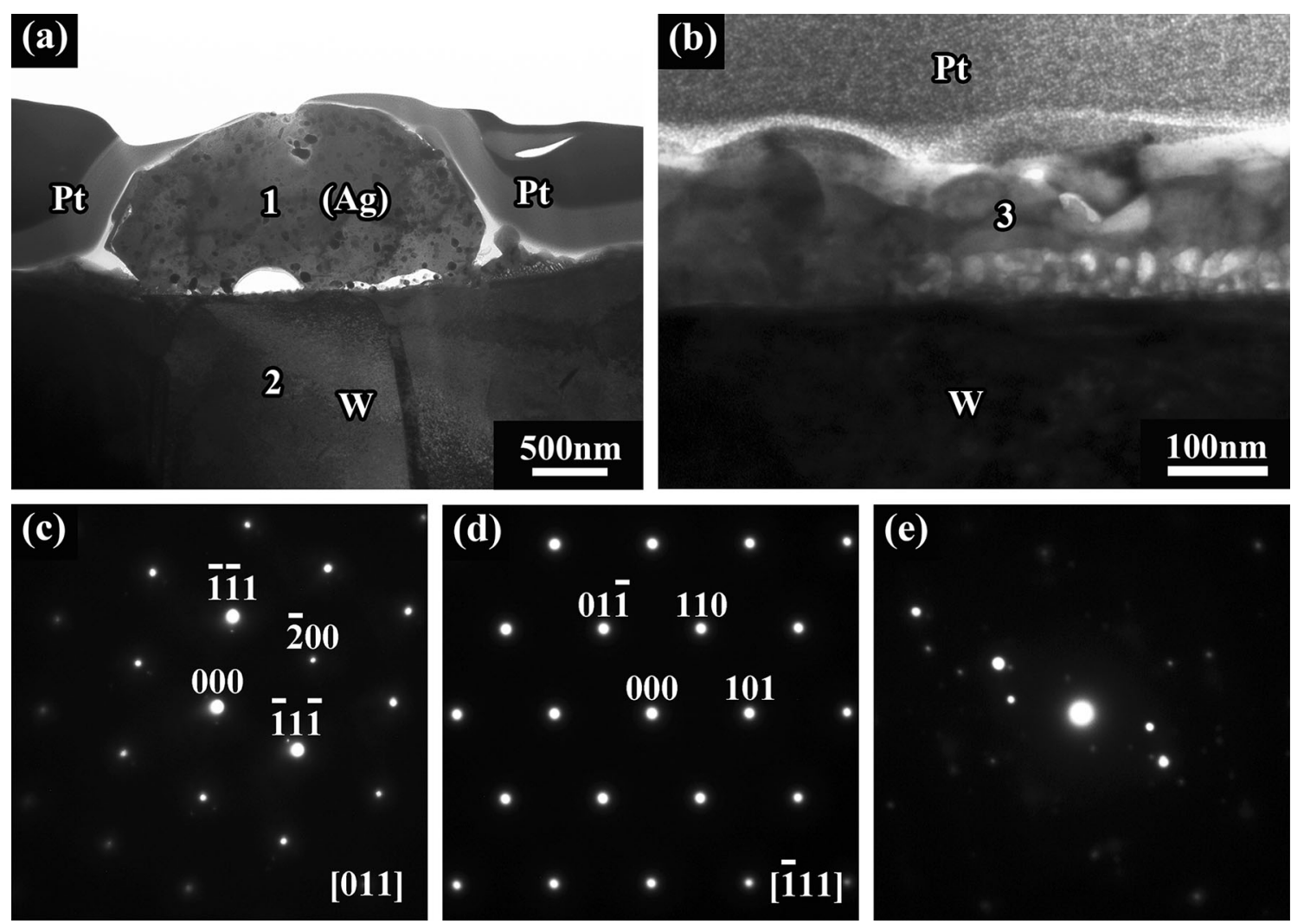

Fig. 9 Examples of TEM data obtained from FIB-cut cross sections through the contact surfaces of the Ag/W contacts from breakers subjected to short-circuit tests: (a-b) BF images; (c-e) SADPs obtained from the regions labeled 1 and 2 in (a) and 3 in (b), respectively

consolidated $\mathrm{W}$ with pores exposing the $\mathrm{Ag} / \mathrm{W}$ phase mixture of the contact below. This is broadly consistent with previous cross-sectional SEM observations of $\mathrm{Ag} / \mathrm{W}$ contacts tested at high applied currents (for example Ref 38, 39).

The surface microstructure was investigated in more detail by TEM imaging and diffraction on FIB-cut cross sections through the contact surfaces, and examples of these data are shown in Fig. 9. The BF TEM image in Fig. 9(a) shows one of the larger deposit particles on the $\mathrm{W}$ surface. The particle is approximately $2.5 \mu \mathrm{m}$ in diameter and the composition measured by EDXS from the region labeled "1" in Fig. 9(a) is 94.2\% $\mathrm{Ag}$ and $5.8 \% \mathrm{Cu}$ (wt. \%). The corresponding SADP in Fig. $9(\mathrm{c})$ is a [011] zone axis pattern for an FCC structure with $\mathrm{a}_{0} \approx 0.41 \mathrm{~nm}$ (c.f. Ag: $\mathrm{a}_{0}=0.4086 \mathrm{~nm}$ ), and so this is a solid solution of $\mathrm{Cu}$ in $\mathrm{Ag}$. Following the convention described by Takemoto et al. (Ref 40), this phase is designated as (Ag). We note that the composition measured from the region labeled " 2 " in Fig. 9(a) is $98.9 \% \mathrm{~W}$ and $1.1 \% \mathrm{Cu}$ (wt. \%) and the corresponding SADP is a [1111] zone axis pattern for a BCC structure with $a_{0} \approx 0.32 \mathrm{~nm}$ (c.f. W: $a_{0}=0.3165 \mathrm{~nm}$ ); this suggests that there is also some $\mathrm{Cu}$ in solid solution within the BCC W layer. There is also a fine nano-crystalline layer of up to $180 \mathrm{~nm}$ in thickness covering the $\mathrm{W}$ layer between the $(\mathrm{Ag})$ particles. A BF image showing an example of this nanocrystalline layer is shown in Fig. 9(b). The measured composition from the region labeled " 3 " is $88.6 \% \mathrm{~W}, 1.0 \% \mathrm{Cu}$, and $10.4 \% \mathrm{O}$ (wt.\%). Analysis of the SADPs from such regions was more challenging because the grains are too small to allow for tilting to low-index zone axes. However, by careful analysis of many off-axis patterns such as Fig. 9(e), which was obtained from the region labeled "3" in Fig. 9(b), it appears that the nano-crystalline layer comprised the triclinic $\mathrm{WO}_{3}$ phase.

\section{Discussion}

As summarized in Fig. 5(d), the overall microstructure of the contacts consists of sintered composite $\mathrm{Ag} / \mathrm{W}$ particles with a pure $\mathrm{Ag}$ infiltrate filling most of the residual porosity. Although the whole contact goes through the same thermal cycle during the infiltration process, the grain size of the $\mathrm{Ag}$ in the sintered composite regions is significantly finer (100$500 \mathrm{~nm})$ than that in the infiltrate $(\gg 1 \mu \mathrm{m})$. This is presumably due to the effects of the $\mathrm{W}$ in the composite regions giving enhanced nucleation of $\mathrm{Ag}$ grains from the melt and/or more limited grain growth in the solid Ag. The contacts from the untested circuit breakers also exhibit a thin nano-crystalline $\mathrm{Ag}$ surface layer, which arises due to the chemical and mechanical finishing processes used during the manufacture of these contacts. As discussed previously (Ref 41), it is this layer that is responsible for the apparent discrepancy between the $\mathrm{Ag}$ to $\mathrm{W}$ ratio revealed in BSE images and EDXS spectra obtained from the contact surface, and the overall contact composition ( $40 \%$ $\mathrm{Ag}, 60 \% \mathrm{~W})$. These contacts exhibit very little variability in the contact resistance $\left(R_{\mathrm{c}}=1.68 \mathrm{~m} \Omega\right.$, standard deviation $=$ $0.3 \mathrm{~m} \Omega$ ), presumably because the contact surfaces are flat, smooth, and uniform on the scale of the ASTM test (contact area of $\approx 10^{-3} \mathrm{~mm}^{2}$ ). We note that these $R_{\mathrm{c}}$ values are slightly higher than those measured in our work (not shown here) for 
freshly manufactured contacts that have not been assembled into breakers $\left(R_{\mathrm{c}} \approx 1.5 \mathrm{~m} \Omega\right)$. The contacts from untested circuit breakers also exhibit a surface discoloration that is visible with the naked eye and surface oxides $\left(\mathrm{WO}_{3}\right.$ and $\left.\mathrm{Ag}_{2} \mathrm{O}\right)$ from the XRD data, neither of which is present on freshly manufactured contacts. Since the resistivities of $\mathrm{WO}_{3}\left(4 \times 10^{4} \Omega \mathrm{cm}\right.$, Ref 42) and $\mathrm{Ag}_{2} \mathrm{O}\left(7 \times 10^{8} \Omega \mathrm{cm}\right.$, Ref 43) are orders of magnitude higher than those of $\mathrm{W}$ and $\mathrm{Ag}$, it is tempting to speculate that the discoloration, the oxide phases, and the increased contact resistance values are related. There are three main reasons why such differences might occur. First, the kinetics of native oxide formation might be enhanced even at ambient conditions because of the nano-crystalline structure exhibited by the surface layer. Thus, the discoloration and oxide formation could simply be a function of the time between the manufacture of the breakers and the analysis performed here. Second, the surface might undergo accelerated oxidation during the short thermal cycle associated with brazing the contact tip onto the breaker arm (see Ref 26). Third, oxidation might occur during postassembly acceptance testing. This latter process is a quality control procedure, wherein each breaker is tripped once at a fixed multiple of the rated current to ensure that the breaker mechanism operates properly. In this context, we note that the term "untested breakers" is somewhat of a misnomer; while these breakers have not undergone the standard UL tests, no breaker leaves the production facility without passing this acceptance test.

There are several distinct differences between the contacts from the "untested" breakers and those from the overload/ temperature-rise tested breakers. The latter contacts exhibit more extensive surface discoloration and oxide formation (including the appearance of $\mathrm{Ag}_{2} \mathrm{WO}_{4}$, which has a resistivity of $8 \times 10^{3}-1.15 \times 10^{4} \Omega \mathrm{cm}$, Ref 44 ), higher and more variable contact resistances $\left(R_{\mathrm{c}}=3.02 \mathrm{~m} \Omega\right.$, standard deviation $=$ $0.94 \mathrm{~m} \Omega$ ), rougher surfaces, and preferential loss of Ag. The mechanism for the Ag loss is unclear. This could be due to direct vaporization of the Ag during the overload cycles, or it may be accelerated oxidation due to the temperature rise with ablation of the oxides by the arc on the subsequent overload cycle(s). Whatever the process involved, it is clear that the nano-crystalline Ag layer has been removed, as has some of the $\mathrm{Ag}$ in a layer of up to $20 \mu \mathrm{m}$ in thickness at the surface. The resulting contact surface is rougher, more porous, and has more oxides present, all of which could contribute to the increases in the mean value and the standard deviation for $R_{\mathrm{c}}$.

The surface degradation is much more complicated for the contacts from endurance-tested breakers. The contacts exhibit more pronounced discoloration and soot formation, the $R_{\mathrm{c}}$ values are three orders of magnitude higher $(2.13 \Omega)$ and are far more variable (standard deviation $=1.73 \Omega$ ), and the XRD data show that the volume of the oxides $\left(\mathrm{WO}_{3}, \mathrm{Ag}_{2} \mathrm{O}\right.$, and $\mathrm{Ag}_{2} \mathrm{WO}_{4}$ ) present on the surface is much greater. This is consistent with previous model switch and arcing studies on $\mathrm{Ag} / \mathrm{W}$ contacts in which arc erosion has been shown to lead to the formation of $\mathrm{WO}_{3}$ and $\mathrm{Ag}_{2} \mathrm{WO}_{4}$, and significant increases in contact resistance (Ref 2, 8, 11, 45). The electron microscopy data show that there are also significant differences in the final surface microstructure across the contact from one side to the other, and this relates to the direction in which the fixed and moving contacts swipe across one another during breaker closure. At the point where the contacts first meet (right-hand side in Fig. 7d and f), there is extensive erosion giving a rough, porous, W-rich surface with significant oxidation. There are also occasional nodular protrusions of pure $\mathrm{W}$, tens of $\mu \mathrm{m}$ in width and height, distributed across these regions. On the opposite side of the contacts, there is a build-up of an oxiderich layer tens of $\mu \mathrm{m}$ in thickness. The likely processes involved in the formation of this complex structure include: evaporation/ablation of material during arcing under load; enhanced surface oxidation due to increases in temperature from arcing and/or mechanical abrasion; and mechanical "sweeping" of material from one side of the contact surface to the other. A combination of such processes could account for most of the microstructural features and phases observed, but it is not possible to determine the relative contributions and sequence of these different mechanisms from the data presented here. We note that the pure $\mathrm{W}$ nodules on the eroded regions of the surface are significantly larger than the coarsest $\mathrm{W}$ powder particles used in the production of these contacts. This suggests that they form by fusing of large $\mathrm{W}$ particles brought into relief by extensive loss of Ag. Thus, the localization of the arc energy at protruding $\mathrm{W}$ particles must raise the local temperatures to above the melting point of pure $\mathrm{W}\left(3422{ }^{\circ} \mathrm{C}\right)$. The extensive loss of $\mathrm{Ag}$ and oxidation of $\mathrm{Ag}$ and $\mathrm{W}$, together with the complex variable microstructure and topography of the resulting surface, would help to explain both the dramatic rise in the mean value of $R_{\mathrm{c}}$ for these contacts and the large standard deviation in the measured values.

The situation is rather more straightforward for the contacts from short-circuit tested breakers. Here again, the contacts exhibit pronounced discoloration and soot formation, and high values of $R_{\mathrm{c}}(12.88 \Omega)$ with very large variation in the measurements (standard deviation $=38.44 \Omega$ ). In this case, however, the extent of the oxidation is more limited with XRD peak intensities for $\mathrm{WO}_{3}$ and $\mathrm{Ag}_{2} \mathrm{O}$ comparable to those from the overload/temperature-rise tested breakers, but no evidence for $\mathrm{Ag}_{2} \mathrm{WO}_{4}$. The tungstate phase is presumably absent because it is relatively unstable and would decompose or vaporize under the intense arc in the short-circuit test (Ref 2, 46). The electron microscopy data reveal a very different microstructure from that exhibited by any of the other contacts. The contact surface is covered by a thick fused $\mathrm{W}$ layer indicating that the overall surface temperature has exceeded $3422{ }^{\circ} \mathrm{C}$ during the intense short-circuit arcing. Since the boiling point of liquid $\mathrm{Ag}$ is only $2162{ }^{\circ} \mathrm{C}$, one would expect the direct vaporization of $\mathrm{Ag}$ to occur. Evidence for this can be seen in the form of Ag-rich islands on the surface of the $\mathrm{W}$ layer; these presumably form by condensation during cooling. It is interesting to note that there is $\mathrm{Cu}$ present both in the Ag-rich islands and in the $\mathrm{W}$ layer. Since there is no $\mathrm{Cu}$ present in the contacts, this must come from the $\mathrm{Cu}$ breaker arm and/or the $\mathrm{Cu}-\mathrm{Ag}$-P braze alloy used to attach the contact to the breaker arm (Ref 26). There are large equi-axed pores in the $\mathrm{W}$ layer that expose the $\mathrm{Ag} / \mathrm{W}$ phase mixture below. These could arise due to de-wetting of the phase mixture by the molten $\mathrm{W}$, but they might also be related to the vaporization of the $\mathrm{Ag}$. Indeed in regions such as that shown in Fig. 8(d), some of the pores in the W layer appear to lie above the larger pores in the contact below, suggesting that they may have opened up due to the vapor pressure built-up by the vaporization of $\mathrm{Ag}$. The large mid-plane cracks can also be explained on the basis of the thermal spike at the surface during short-circuit arcing. Since there is no evidence of melting in the $\mathrm{Cu}$ breaker arm, we estimate that the peak temperature difference across the contact is at least $2500{ }^{\circ} \mathrm{C}$. The very high thermal stresses that would result from this temperature gradient would be exacerbated locally by differences in the 
thermal expansion coefficients of $\mathrm{Ag}$ and $\mathrm{W}$ and by residual porosity. The very high mean values of $R_{\mathrm{c}}$ and standard deviation in the individual measurements can be explained as the combined effects of the high resistivity nano-crystalline oxide layer covering the $\mathrm{W}$ crust; the porosity in the $\mathrm{W}$ crust and in the underlying $\mathrm{Ag} / \mathrm{W}$ mixtures; and the mid-plane cracking that dramatically reduces the effective cross section of the contact.

It is important to note that while we have reported dramatic changes in the structure morphology and properties of the Ag/ W contacts during standard UL tests, all of the samples studied here passed the tests. Thus, all of the contacts exhibited the required calibration performance after being subjected to the overload/temperature-rise, endurance, or short-circuit test sequence. As such, not only do our observations give a useful insight into the processes occurring during these tests, but also they demonstrate the remarkable durability of these circuit breaker contact materials. Any alternate metallic formulations that might be developed to replace the expensive Ag in these materials will clearly need to match the properties and performance of the existing materials.

\section{Summary}

The near-surface microstructural characteristics and contact resistance behavior of the $\mathrm{Ag} / \mathrm{W}$ contacts from commercial $120 \mathrm{~V}, 30 \mathrm{~A}$ circuit breakers in the as-manufactured condition and after standardized UL overload/temperature-rise, endurance, and short-circuit testing have been investigated, and the main findings are as follows:

1. The overall microstructure of the $\mathrm{Ag} / \mathrm{W}$ contacts comprised three different constituents: sintered Ag/W composite particles with fine-grained (100-500 nm) Ag and coarse-grained $(\gg 1 \mu \mathrm{m}) \mathrm{W}$, coarse-grained $(\gg 1 \mu \mathrm{m})$ pockets of Ag infiltrate, and a nano-crystalline Ag surface layer. The three different $\mathrm{Ag}$ grain sizes arise due to the effects of different steps in the manufacturing process.

2. Untested breaker contacts exhibit low, uniform contact resistances $\left(R_{\mathrm{c}}=1.68 \mathrm{~m} \Omega\right.$, standard deviation $\left.=0.3 \mathrm{~m} \Omega\right)$, but some surface oxides $\left(\mathrm{WO}_{3}\right.$ and $\left.\mathrm{Ag}_{2} \mathrm{O}\right)$ are present even at this stage. This can be attributed to some combination of native oxide formation, the thermal cycle for brazing of the contact to the breaker arm, and the postproduction quality control acceptance test.

3. After UL overload/temperature-rise testing, the contacts exhibit somewhat higher and more variable values of $R_{\mathrm{c}}$ (3.02 $\mathrm{m} \Omega$, standard deviation $=0.94 \mathrm{~m} \Omega$ ), corresponding to the development of a more porous $\mathrm{W}$-rich surface layer with oxide phases including $\mathrm{Ag}_{2} \mathrm{WO}_{4}$. The preferential loss of $\mathrm{Ag}$ from the surface layer is consistent with Ag either evaporating from the surface or oxidizing preferentially and being ablated from the surface.

4. The UL endurance testing results in contacts with much higher and more variable contact resistances (2.13 $\Omega$, standard deviation $=1.73 \Omega$ ), and dramatic increases in the amount of $\mathrm{WO}_{3}, \mathrm{Ag}_{2} \mathrm{WO}_{4}$, and $\mathrm{Ag}_{2} \mathrm{O}$ present at the surface. The contacts also show significant microstructural variation across the surface: on one side, there is extensive erosion with a W-rich surface and fused nod- ules of pure $\mathrm{W}$, and on the other there is extensive buildup of oxide phases. These microstructural features are related to sweeping of material across the surface due to the swiping motion of the contacts over one another during breaker closure.

5. The contacts from the breakers subjected to UL short-circuit testing exhibited even higher and more variable contact resistances $(12.88 \Omega$, standard deviation $=38.44 \Omega)$, but much lower levels of oxide phases at the surface. These features correspond to the melting and re-solidification of $\mathrm{W}$ during testing to form a crust across the contact surface. Most of the $\mathrm{Ag}$ at the surface is lost by vaporization during this process but some condenses as fine islands across the crust surface during cooling. The contacts also develop large mid-plane cracks due to the thermal stresses that develop during testing.

\section{Acknowledgments}

This work was supported by a grant from GE Energy Management - Industrial Solutions under a GE-UConn partnership agreement, and by the award of GE Graduate Fellowships to Haibo Yu and M. Tumerkan Kesim.

\section{References}

1. P.V. Minakova, M.L. Grekova, A.P. Kresanov, and L.A. Kryachko, Composites for Contacts and Electrodes (A Review), Powder Metall. Met. Ceram., 1995, 34(7-8), p 370-385

2. P.G. Slade, Variations in Contact Resistance Resulting from Oxide Formation and Decomposition in Ag-W and Ag-WC-C Contacts Passing Steady Currents for Long Time Periods, IEEE Trans. Compon. Hybrids Manuf. Technol., 1986, 9(1), p 3-16

3. C.-H. Leung and H.J. Kim, A Comparison of Ag/W, Ag/WC, and Ag/ Mo Electrical Contacts, IEEE Trans. Compon. Hybrids Manuf. Technol., 1984, 7(1), p 69-75

4. T. Bregel, W. Krauss-Vogt, R. Michal, and K.E. Saeger, On the Application of W/Cu Materials in the Fields of Power Engineering and Plasma Technology, IEEE Trans. Compon. Hybrids Manuf. Technol., 1991, 14(1), p 8-13

5. C.-H. Leung and P.C. Wingert, Microstructure Effects on Dynamic Welding of $\mathrm{Ag} / \mathrm{W}$ Contacts, IEEE Trans. Compon. Hybrids Manuf. Technol., 1988, 11(1), p 64-67

6. C.-H. Leung, P.C. Wingert, and H.J. Kim, Comparison of Reignition Properties of Several Ag/W, Ag/WC, and Ag/Mo Electrical Contact Materials, IEEE Trans. Compon. Hybrids Manuf. Technol., 1986, 9(1), p 86-91

7. T. Mutzel and R. Niederreuther, Development of Contact Material Solutions for Low-Voltage Circuit Breaker Applications (2), Proceedings of the 57th IEEE Holm Conference on Electrical Contacts, September 11-14, 2011, p 1-6

8. J.J. Shea, Erosion and Resistance Characteristics of $\mathrm{AgW}$ and $\mathrm{AgC}$ Contacts, IEEE Trans. Compon. Packag. Technol., 1999, 22(2), p 331336

9. F. Findik and H. Uzun, Microstructure, Hardness and Electrical Properties of Silver-Based Refractory Contact Materials, Mater. Des., 2003, 24(7), p 489-492

10. T. Mutzel, P. Braumann, and R. Niederreuther, Development of Contact Material Solutions for Low-Voltage Circuit Breaker Applications (1), Proceedings of the 56th IEEE Holm Conference on Electrical Contacts, October 4-7, 2010, p 1-6

11. P.G. Slade, Effect of the Electric Arc and the Ambient Air on the Contact Resistance of Silver, Tungsten, and Silver-Tungsten Contacts, J. Appl. Phys., 1976, 47(8), p 3438-3443

12. P. Borkowski, E. Walczuk, K. Frydman, and D. Wojcik-Grzybek, Switching Properties of Contacts Made of Silver-Tungsten And SilverTungsten-Rhenium Composite Materials, Proceedings of the 59th 
IEEE Holm Conference on Electrical Contacts, September 22-25, 2013, p 1-10

13. P.C. Wingert, The Detection and Effects of Oxide Layers on SilverRefractory Contact Surfaces, Proceedings of the 43rd IEEE Holm Conference on Electrical Contacts, October 20-22, 1997, p 104-114

14. M. Lindmayer and M. Roth, Contact Resistance and Arc Erosion of W/ Ag and WC/Ag, IEEE Trans. Compon. Hybrids Manuf. Technol., 1979, 2(1), p 70-75

15. K. Kaliszuk, K. Frydman, D. Wojcik-Grzybek, W. Bucholc, E. Walczuk, P. Borkowski, and D. Zasada, Arc Erosion Tests and Study of Surface of Ag-WC Contacts After Arc Switching Operations, Proceedings of the 50th IEEE Holm Conference on Electrical Contacts and the 22nd International Conference on Electrical Contacts, September 20-23, 2004, p 75-82

16. O. Kubaschewski and B.E. Hopkins, Oxidation of Metals and Alloys, 2nd ed., Butterworths, London, 1962

17. M. Braunovic, V.V. Konchits, and N.K. Myshkin, Electrical Contacts: Fundamentals, Applications and Technology, CRC Press, Boca Raton, 2006

18. P.G. Slade, W. Li, L.D. Loud, and R.E. Haskins Jr., The Unusual Electrical Erosion of High Tungsten Content, Tungsten Copper Contacts Switching Load Current In Vacuum, Proceedings of the 46th IEEE Holm Conference on Electrical Contacts, September 25-27, 2000, p 139-152

19. V. Behrens, T. Honig, and A. Kraus, Tungsten and Tungsten Carbide Based Contact Materials Used in Low Voltage Vacuum Contactors, Proceedings of the 45th IEEE Holm Conference on Electrical Contacts, October 4-6, 1999, p 105-110

20. Standard for Safety, Molded-Case Circuit Breakers, Molded-Case Switches, and Circuit-Breaker Enclosures, ANSI/UL Standard 489, 1996

21. C.W. Kimblin and R.W. Long, Low-Voltage Power Circuit Breakers and Molded Case Circuit Breakers-A Comparision of Test Requirements, IEEE Industrial and Commercial Power Systems Technical Conference, August, 1999

22. M. Higginson and D.B. Durocher, Proper Application \& Maintenance of Molded Case Breakers to Assure Safe and Reliable Operation, IEEE IAS Electr. Saf. Workshop, 2009, 2-6, p 1-12

23. Z. Aslanoglu, Y. Karakaş, M.L. Öveçoglu, and B. Özkal, Effects of Nickel Addition on Properties of Ag-W Electrical Contact Materials, Powder Metall., 2001, 44(1), p 77-81

24. G.J. Witter and W.R. Warke, A Correlation of Material Toughness, Thermal Shock Resistance, and Microstructure of High Tungsten, Silver-Tungsten Composite Materials, IEEE Trans. Parts Hybrids Packag., 1975, 11(1), p 21-29

25. C.W. Corti, Sintering Aids in Powder Metallurgy, Platin. Met. Rev., 1986, 30(4), p 184-195

26. H. Yu, Y. Sun, S.P. Alpay, and M. Aindow, Microstructure Effects in Braze Joints Formed Between Ag/W Electrical Contacts and Sn-Coated Cu using Cu-Ag-P Filler Metal, J. Mater. Sci., 2015, 50(1), p 324-333

27. Standard Practice for Construction and Use of a Probe for Measuring Electrical Contact Resistance, ASTM Standard B 667-97, 2009

28. J. Shea and J.A. Bindas, Measuring Molded Case Circuit Breaker Resistance, IEEE Trans. Compon. Hybrids Manuf. Technol., 1993, 16(2), p 196-202
29. P.G. Slade, The Switching Performance of Refractory Carbide-Silver Contacts, IEEE Trans. Compon. Hybrids Manuf. Technol., 1979, 2(1), p $127-133$

30. M. Antler, Survey of Contact Fretting in Electrical Connectors, IEEE Trans. Compon. Hybrids Manuf. Technol., 1985, 8(1), p 87-104

31. A. Beloufa, Conduction Degradation by Fretting Corrosion Phenomena for Contact Samples Made of High-Copper Alloys, Tribol. Int., 2010, 43(11), p 2110-2119

32. I.H. Brockman, C.S. Sieber, and R.S. Mroczkowski, A Limited Study of the Effects of Contact Normal Force, Contact Geometry and Wipe Distance on the Contact Resistance of Gold-Plated Contacts, Proceedings of the 38th Electronics Components Conference, May 9-11, 1988, p 198-207

33. R. Diehl, G. Brandt, and E. Salje, The Crystal Structure of Triclinic $\mathrm{WO}_{3}$, Acta Crystallogr. Sect. B, 1978, 34, p 1105-1111

34. S.S. Kabalkina, S.V. Popova, N.R. Serebryanaya, and L.F. Vereshchagin, A New Modification of $\mathrm{Ag}_{2} \mathrm{O}$ with Layered Structure, Dokl. Akad. Nauk SSSR, 1963, 152, p 853-854

35. P.M. Skarstad and S. Geller $\left(\mathrm{W}_{4} \mathrm{O}_{16}\right)^{8-}$ Polyion in the High Temperature Modification of Silver Tungstate, Mater. Res. Bull., 1975, 10(8), p 791-800

36. B.M. Gatehouse and P. Leverett, Crystal Structures of Silver Dimolybdate, $\mathrm{Ag}_{2} \mathrm{Mo}_{2} \mathrm{O}_{7}$, and Silver Ditungstate, $\mathrm{Ag}_{2} \mathrm{~W}_{2} \mathrm{O}_{7}$, J. Chem. Soc. Dalton, 1976, 5, p 1316-1320

37. P.C. Wingert, Testing of the Thermal-Stress-Cracking Characteristics of Silver-Refractory Contacts, Proceedings of the 41st IEEE Holm Conference on Electrical Contacts, October 2-4, 1995, p 338-345

38. P.C. Wingert, The Effects of Nickel on the Switching Performance of Silver-Tungsten-Based Contacts, Proceedings of the 39th IEEE Holm Conference on Electrical Contacts, September 27-29, 1993, p 111-115

39. J.J. Shea, Polymeric Arc Chamber Walls Influence on AGW/AGC Contact Resistance, IEEE Trans. Compon. Packag. Technol., 2000, 23(2), p 205-210

40. T. Takemoto, I. Okamoto, and J. Matsumura, Phase Diagram of Cu-Ag$\mathrm{P}$ and Cu-Sn-P Ternary Brazing Filler Metals, Trans. JWRI, 1987, 16(2), p 73-79

41. H. Yu, Y. Sun, S.P. Alpay, and M. Aindow, Characterization of the Surface Layer of Ag/W Electrical Contacts, Microsc. Microanal., 2014, 20(Suppl. 3), p 860-861

42. N. Kaneki, H. Hara, K. Shimada, and T. Shimizu, Effect of Atmosphere on Resistivity of $\mathrm{WO}_{3}$ Ceramics, J. Am. Ceram. Soc., 1976, 59(7-8), p 368-369

43. Y. Abe, T. Hasegawa, M. Kawamura, and K. Sasaki, Characterization of Ag Oxide Thin Films Prepared by Reactive RF Sputtering, Vacuum, 2004, 76(1), p 1-6

44. A. Sreedevi, K.P. Priyanka, S.R. Mary, E.M. Mohammed, and T. Varghese, Nanophase $\alpha$-Silver Tungstate for Potential Applications in Light Emitting Diodes and Gate Dielectrics, Adv. Sci. Eng. Med., 2015, 7(6), p 498-505

45. R. Michal and K.E. Saeger, Metallurgical Aspects of Silver-Based Contact Materials for Air-Break Switching Devices for Power Engineering, IEEE Trans. Compon. Hybrids Manuf. Technol., 1989, 12, p 71-81

46. C.-H. Leung, R.C. Bevington, P.C. Wingert, and H.J. Kim, Effects of Processing Methods on the Contact Performance Parameters for SilverTungsten Composite Materials, IEEE Trans. Compon. Hybrids Manuf. Technol., 1982, 5(1), p 23-31 